Article

\title{
Energy Harvesting Backpacks for Human Load Carriage: Modelling and Performance Evaluation
}

\author{
Ledeng Huang, Ruishi Wang, Zhenhua Yang and Longhan Xie * \\ Shien-Ming Wu School of Intelligent Engineering, South China University of Technology, \\ Guangzhou 511442,China; meldhuang@mail.scut.edu.cn (L.H.); rui_shi_wang@163.com (R.W.); \\ mtzhyoung@gmail.com (Z.Y.) \\ * Correspondence: melhxie@scut.edu.cn; Tel.: +86-137-2985-9001
}

Received: 4 June 2020; Accepted: 23 June 2020; Published: 28 June 2020

\begin{abstract}
In recent years, there has been an increasing demand for portable power sources as people are required to carry more equipment for occupational, military, or recreational purposes. The energy harvesting backpack that moves relative to the human body, could capture kinetic energy from human walking and convert vertical oscillation into the rotational motion of the generators to generate electricity. In our previous work, a light-weight tube-like energy harvester (TL harvester) and a traditional frequency-tuneable backpack-based energy harvester (FT harvester) were proposed. In this paper, we discuss the power generation performance of the two types of energy harvesters and the energy performance of human loaded walking, while carrying energy harvesting backpacks, based on two different spring-mass-damper models. Testing revealed that the electrical power in the experiments showed similar trends to the simulation results, but the calculated electrical power and the net metabolic power were higher than that of the experiments. Moreover, the total cost of harvesting $(\mathrm{TCOH})$, defined as additional metabolic power in watt required to generate $1 \mathrm{~W}$ of electrical power, could be negative, which indicated that there is a chance to generate $6.11 \mathrm{~W}$ of electricity without increasing the metabolic cost while carrying energy harvesting backpacks.
\end{abstract}

Keywords: energy harvesting; suspended-load backpack; spring-mass-damper model; human motion

\section{Introduction}

Walking in the fields while carrying heavy loads is a common task for soldiers and hikers. Generally, heavier loads often induce more metabolic cost [1,2], higher ground reaction forces [3,4], and greater muscle strain in shoulders $[5,6]$. As technology progresses, people are required to carry more equipment for occupational, military, or recreational purposes. However, the electronic devices are generally powered by rechargeable batteries, which increase the load applied to the human body and could accelerate fatigue and increase the risk of injury. To address this problem, energy harvesting techniques that convert human kinetic energy to electrical energy have received increasing attention [7-12].

Considering that people are often carrying loads in a backpack, making alternations to a normal backpack structure and installing energy harvesters in the backpack provide an opportunity to generate electrical power from the loads. In addition, as most of the other energy harvesters are directly worn on the human body, such as on the leg [13], at the knee [14], or the ankle [15], some limit the freedom of the lower limbs or cannot be used under complex walking conditions. The alternations to a backpack may also have the capability to reduce the negative biomechanical and kinematic effects on the user and improve the user-device interaction. It has been reported that the suspended-load backpack, which moves relative to the human body, could capture kinetic energy from human walking and running and convert vertical oscillation into the rotational motion of the generators to generate 
electricity [16-19]. The suspension system could reduce the vertical movement of the backpack relative to the ground by adjusting spring stiffness and damping coefficients to change the oscillating phase of the backpack. Therefore, the process reduces the accelerative forces applied on the shoulders of the human body, and then potentially improving the economy of loaded walking [20-23]. Researchers have previously used body-load spring-mass-damper models of vertical motion, based on traditional suspended-load backpacks in which the suspended load oscillated vertically relative to the human body to analyze the energy performance of human walking during load carriage [24,25]. It has been found from these models that cleverly choosing the suspension system parameters can save energy expenditure of load carriage. Given energy harvesting techniques, aimed at low power loss and improving energy efficiency, have been proved feasible [26-28], it is possible that the suspended-load backpacks could capture the maximum amount of energy during human motion while minimizing the participant's metabolic rate.

However, in terms of the previously designed suspended-load backpacks, only two energy harvesting backpacks succeeded in generating electricity, while simultaneously reducing the peak forces on shoulders, and the metabolic cost of the participants were not measured in the experiments $[17,29]$. For the spring-mass-damper models, previous studies focused on how elastically-suspended loads can affect the energetic cost of human walking, but the body-load model, which is also considered energy harvesting, was not proposed. Additionally, the weight of the oscillating frames in the suspension system was not taken into account in these models, which actually caused an increase in human metabolic cost, such as the mass of Rome's backpack (5.6 kg) [16], Xie's backpack (6.5 kg) [17], and Talarico's backpack (6.8 kg) [18]. In general, there is little research discussing the relationship between the generated electrical power and metabolic power during loaded walking.

In this paper, we discussed the power generation performance of the two types of energy harvesters and the energy performance of human loaded walking, while carrying energy harvesting backpacks, based on two different spring-mass-damper models. Our goal was to obtain the maximum electricity while minimizing the participant's metabolic consumption. In our previous studies, a light-weight tube-like energy harvester (TL harvester) which was embedded in a backpack [30] and a traditional frequency-tuneable backpack-based energy harvester (FT harvester), which could also relieve accelerative load [17] were proposed. Given that the electromagnetic generators have high energy density and do not need smart materials and external voltage source, compared to the piezoelectric and electrostatic generators [31,32], electromagnetic generators were used to produce electricity in both harvesters. The TL harvester utilized relative swing between the backpack and human body while the FT harvester relied on a framework and gear trains to produce vertical movement. The total cost of harvesting (TCOH), which was defined as an additional metabolic power in watts, was required to generate $1 \mathrm{~W}$ of electrical power [33]. It was used to evaluate the relationship between the generated power and additional metabolic power. Furthermore, experiments were performed to evaluate the performance of the two energy harvesting backpacks.

\section{Methods}

\subsection{Dynamic Model of the System}

\subsubsection{Spring-Mass-Damper Slip Model}

We developed the spring-mass-damper slip model of the suspension system, which was presented by Ackerman [24] and experimentally verified on a legged robot [34], to investigate the energy performance of human body with a FT harvester based energy harvesting backpack (Figure 1a). The slip model can be divided into three parts, including a simple leg model, a body load, and a vertical suspension system. In the simple leg model, the dynamics of the legs are represented by the spring stiffness $k_{1}$, the damping coefficient $c_{1}$, and the "effective length" $L_{t}$, which provides input for the system. Because the motion of the body center of mass (CoM) in the vertical direction during walking could be seen as a sinusoid with fixed frequency and amplitude [35], the effective length function $L_{t}$ 
can be used as an actuator to vary the equilibrium length of the spring-leg to achieve motion similar to the vertical center of mass displacement of the human body. Its value is given as a harmonic function: $L_{t}=Y \sin (w t)$, where $w$ is the frequency of the human center of mass during locomotion, which can be empirically approximated to be a function of the human walking speed $v$ and leg length $R$ [36], as shown in Equation (1), and $Y$ is the leg actuator oscillation amplitude which depends on $w, R$ and $v$ [37], as shown in Equation (2):

$$
\begin{gathered}
w=9.45(v / R)^{0.57} \\
Y=\frac{R}{2}\left(1-\sqrt{1-\left(\frac{0.963 \pi v}{R w}\right)^{2}}\right)-0.0157 R .
\end{gathered}
$$

(a)

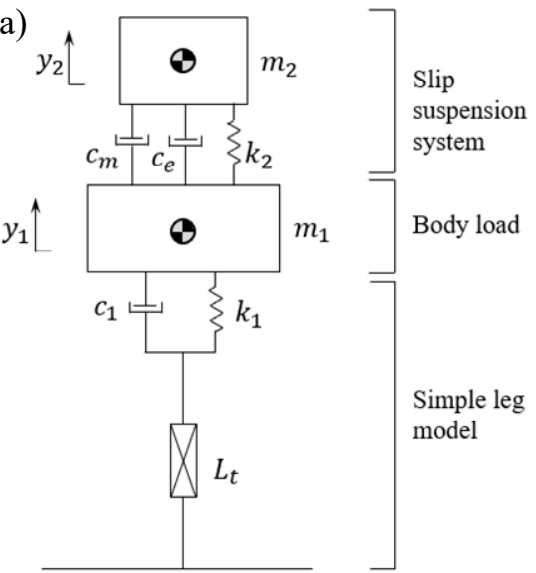

(b)

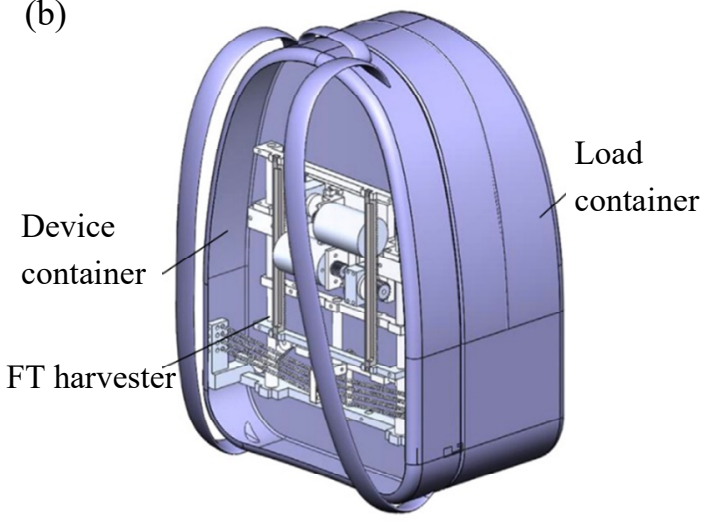

Figure 1. Schematic of the FT harvester: (a) Spring-mass-damper slip model; (b) FT energy harvester assembly mounted in the backpack [17].

The backpack load $m_{2}=m_{l}+m_{h}$ is connected to the body via a suspension system with the spring stiffness $k_{2}$ and damping coefficient, where $m_{l}$ and $m_{h}$ are the masses of the load in the backpack and the harvester, respectively. The damping coefficient $c_{2}$ is composed of the mechanical damping coefficient $c_{m}$ generated by friction between components and electrical damping coefficient $c_{e}$ generated by the operation of the generator. It can be expressed as: $c_{2}=c_{m}+c_{e}$. Details on the mechanical design of the suspension system can be found in [17] (Figure 1b). As for the body load, because we take into account the weight of the framework attached to the back of the body, the total weight of the body load is $m_{1}=m_{b}+m_{f}$, where $m_{b}$ and $m_{f}$ are the masses of the human body and the framework, respectively. The dynamic equations of this model are given by,

$$
\left\{\begin{array}{c}
m_{1} \ddot{y}_{1}+\left(k_{1}+k_{2}\right) y_{1}-k_{2} y_{2}+\left(c_{1}+c_{2}\right) \dot{y}_{1}-c_{2} \dot{y}_{2}=k_{1} L_{t}+c_{1} \dot{L}_{t} \\
m_{2} \ddot{y}_{2}+k_{2} y_{2}-k_{2} y_{1}+c_{2} \dot{y}_{2}-c_{2} \dot{y}_{1}=0
\end{array}\right.
$$

where $y_{1}$ and $y_{2}$ are the vertical translations of the body and the backpack, respectively. The representative parameters of the two models used to simulate human walking are shown in Table 1. We select a representative participant (height: $1.8 \mathrm{~m}$, leg length: $0.95 \mathrm{~m}$, weight: $75 \mathrm{~kg}$, speed: $5.5 \mathrm{~km} / \mathrm{h}$ ) from experiments in [17] to obtain leg length, walking speed and mass of the human body. The effective leg stiffness and damping values are estimated by zhang et al. [38]. The masses of the FT harvester based framework $(5 \mathrm{~kg})$, load $(15 \mathrm{~kg})$ and harvester $(1.5 \mathrm{~kg})$ are adapted from our previous studies in $[17,30]$. The suspension stiffness and damping values are variables in the simulation. 
Table 1. Parameters for the spring-mass-damper model.

\begin{tabular}{cccc}
\hline Parameter & Description & Values for Slip Model & Values for Swing Model \\
\hline$R(\mathrm{~m})$ & Leg length [17] & 0.95 & 0.95 \\
$v(\mathrm{~km} / \mathrm{h})$ & Walking speed [17] & 5.5 & 5.5 \\
$k_{1}(\mathrm{~N} / \mathrm{m})$ & Effective leg stiffness [38] & 28,500 & 28,500 \\
$c_{1}(\mathrm{~N} \mathrm{~s} / \mathrm{m})$ & Effective leg damping [38] & 950 & 950 \\
$k_{2}(\mathrm{~N} / \mathrm{m})$ & Suspension stiffness & Variable & Variable \\
$c_{2}(\mathrm{~N} \mathrm{~s} / \mathrm{m})$ & Suspension damping & Variable & Variable \\
$m_{1}(\mathrm{~kg})$ & Body load [17,30] & 80 & 75 \\
$m_{2}(\mathrm{~kg})$ & Backpack load [17,30] & 16.5 & 16.5 \\
\hline
\end{tabular}

\subsubsection{Spring-Mass-Damper Swing Model}

The spring-mass-damper swing model was used to study the energy performance of human body with a TL harvester based energy harvesting backpack. The swing model also consists of three parts, including a simple leg model, a body load, and a swing suspension system (Figure 2a). The simple leg model is the same as what has been presented in Section 2.1.1. Since there is no framework attached to the back of the body, the total body load $m_{1}=m_{b}$. In the swing suspension system, the backpack's belt is fixed at the waist $A$, and the harvester is embedded at the position $B$ in the backpack. One end of the straps is connected to the harvester and the other end is fixed on the shoulders of the body $C$. Details on the mechanical design of the suspension system can be found in [30] (Figure 2b). The backpack rotates with a fixed axis relative to point $A$, leading to the changing length of pulling wire $x_{b c}$. The dynamic equation of this model is given by,

$$
-I_{A} \ddot{\theta}=\left(k_{2} x_{b c}+c_{2} \dot{x}_{b c}\right) \frac{d_{b} d_{c} \sin \theta}{x_{b c}+s}-m_{2} g \frac{d_{c}}{2} \sin \theta+m_{2} w^{2} Y \sin (w t) \frac{d_{c}}{2} \sin \theta
$$

where $I_{A}$ is the equivalent of the moment of inertia (MOI) of the backpack, which is comprised of the MOI of the harvester and the load in the backpack. $s$ is the length between backpack $B$ and shoulder $C$ at the equilibrium position. $\theta$ is the angle between the backpack axis and the vertical axis, which is formulated as,

$$
\theta=\arccos \left(\frac{d_{b}^{2}+d_{c}^{2}-\left(x_{b c}+s\right)^{2}}{2 d_{b} d_{c}}\right)
$$

where $d_{b}$ and $d_{c}$ are the lengths between shoulder $C$ and waist $A$ and between backpack $B$, and waist $A$, respectively.
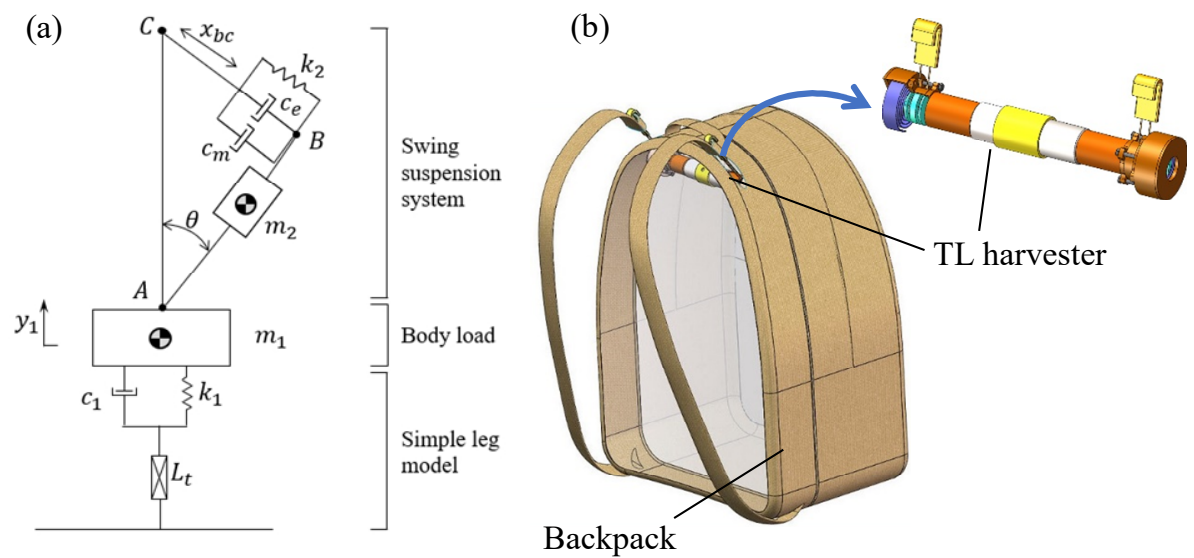

Figure 2. Schematic of the TL harvester: (a) Spring-mass-damper swing model; (b) TL energy harvester assembly mounted in the backpack [30]. 


\subsection{Electrical Power Generation}

Based on the above two models, the electrical power generation can be calculated and compared. Assuming that the velocity at the harvester input is $\dot{u}$, the angular velocity of the generator is defined as $\dot{\theta}_{g}=i_{\mathrm{g}} \dot{u} / r$, where $i_{\mathrm{g}}$ is the ratio of the gearbox and $r$ is the shaft radius at the input of the gearbox. During human walking, the generator produces a voltage $E$, as follows,

$$
E=K_{\mathrm{g}} \dot{\theta}_{g}=K_{\mathrm{g}} i_{\mathrm{g}} \dot{u} / r
$$

where $K_{\mathrm{g}}$ is the back electromotive force constant of the generator. For the energy harvester, when the internal resistance and external load resistance are $R_{i}$ and $R_{o}$ respectively, the transient electrical power of the generator $P_{\text {gen }}$ is given by:

$$
P_{\text {gen }}=c_{e} \dot{u}^{2}=E^{2} /\left(R_{i}+R_{o}\right) .
$$

Then, substituting Equation (6) into Equation (7), the electrical damping coefficient of the energy harvester $c_{e}$ is given by,

$$
c_{e}=\left(K_{\mathrm{g}} i_{\mathrm{g}} / r\right)^{2} /\left(R_{i}+R_{o}\right)
$$

and the transient output power through the external load resistance can be written as follows:

$$
P_{\text {out }}=\left(\frac{K_{\mathrm{g}} i_{\mathrm{g}}}{r}\right)^{2} \frac{R_{o}}{\left(R_{o}+R_{i}\right)^{2}} \dot{u}^{2} .
$$

For a given generator, the electrical damping force and transient output power are functions of the velocity $\dot{u}$ and the gear ratio $i_{\mathrm{g}}$. From Equation (9), the maximum power is given by $\left(\frac{K_{\mathrm{g}} i_{\mathrm{g}}}{r}\right)^{2} \frac{\dot{u}^{2}}{4 R_{i}}$, when $R_{i}=R_{o}$. In the aforementioned two models, the calculated $\dot{y}_{1}-\dot{y}_{2}$ and $\dot{x}_{b c}$ represent the velocity $\dot{u}$ respectively. Then, the average output power $P_{a}$, which is obtained by integrating the transient output power over a gait cycle $T=2 \pi / w$ and dividing by $T$, is given by:

$$
P_{a}=1 / T \int_{0}^{T} P_{\text {out }} d t
$$

In this part, we compare the output power of the two models under different spring stiffness $k_{2}$ and gear ratios $i_{\mathrm{g}}$. As expected, in the slip model, for each gear ratio, $P_{a}$ is the highest when the natural frequency of the load suspension $w_{f}=\sqrt{k_{2} / m_{2}}$ is turned near to the walking frequency $w$ (Figure $3 a$ ). Additionally, with the increase of the gear ratio, the harvester is less sensitive to change in stiffness. This is because a higher gear ratio will produce a greater electrical damping force, resulting in slower velocity $\dot{u}$, and the average output power changes more smoothly. At the load mass of $15 \mathrm{~kg}$ and the velocity of $5.5 \mathrm{~km} / \mathrm{h}$, for a selected generator, when the gear ratio is between 15 and 20, the maximum value of $14 \mathrm{~W}$ of average output power can be obtained. In contrast, in the swing model, the average output power decreases with the increase of stiffness, and only about $7 \mathrm{~W}$ of maximum average output power can be obtained at the gear ratio of 20. Compared to the slip model, the relative velocity $\dot{u}$ of the swing model is slower under the same conditions, causing lower output power. 

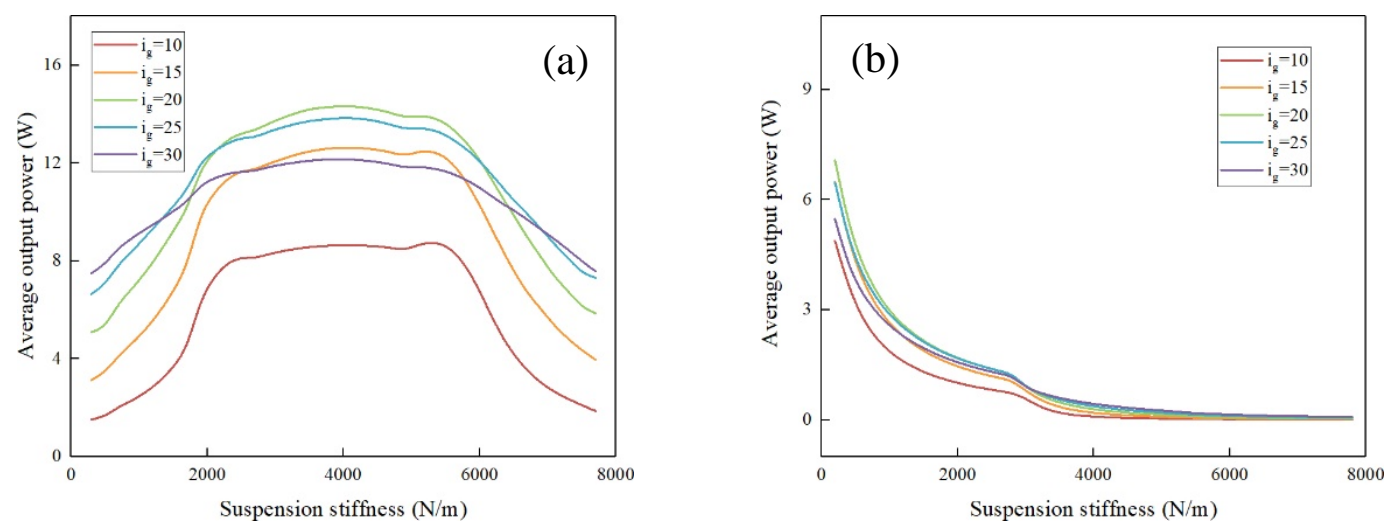

Figure 3. Average output power versus spring stiffness under different gear ratios with walking velocity $v=5.5 \mathrm{~km} / \mathrm{h}$ and load mass $m_{l}=15 \mathrm{~kg}$ : (a) Slip model; (b) Swing model.

\subsection{Human Net Metabolic Power and TCOH Calculation}

The instantaneous net mechanical power of the leg actuator $P(t)$, which is derived from muscles in human body, is calculated by multiplying the leg force $F_{l}$ with the velocity $\dot{L}_{t}$ and dividing by the mass of human body $m_{b}$, where:

$$
\begin{gathered}
F_{l}=k_{1}\left(L_{t}-y_{1}\right)+c_{1}\left(\dot{L}_{t}-\dot{y}_{1}\right)+\left(m_{1}+m_{2}\right) g \\
P(t)=F_{l} \dot{L}_{t} / m_{b} .
\end{gathered}
$$

The net mechanical work done by the leg actuator is equal to the net energy lost through the leg and suspension damping. Because the dynamics of the leg actuator are vertically strained, we approximate that the net mechanical power done by the leg actuator to vertically oscillate the system over each step is correlated with the human net metabolic power. The mean power of the effective leg $P_{m}$, which is considered as human net metabolic power input in the system, is obtained by integrating the instantaneous net mechanical power $P(t)$ over a gait cycle $T=2 \pi / w$ and dividing by $T$, i.e., the mean value of the product of the leg force $F_{l}$ and the velocity $\dot{L}_{t}$ per step. Moreover, muscles perform positive work with an efficiency of $25 \%$ when the body CoM is upward and negative work is performed by muscles at an efficiency of $-120 \%$ for downward motion $[39,40]$. Therefore, after considering the efficiency $\eta_{t}$ of muscles conducting mechanical work, the net metabolic power is given as:

$$
P_{m}=1 / T \int_{0}^{T} P(t) / \eta_{t} d t=1 / T \int_{0}^{2 \pi / w} F_{l} \dot{L}_{t} / \eta_{t} d t, \eta_{t}=\left\{\begin{array}{l}
25 \% \text { if } P(t)>0 \\
-120 \% \text { if } P(t)<0
\end{array} .\right.
$$

To quantify the relationship between the generated power and additional metabolic power during harvesting, the total cost of harvesting (TCOH) was proposed by Shepertycky et al. [33], which is defined as:

$$
\mathrm{TCOH}=\frac{\text { metab. power of elec. engagement }- \text { metab. power of normal walking }}{\text { elec. power }} .
$$

Based on the calculation method above, the net metabolic power can be used to investigate the energetic cost of human walking with an energy harvesting backpack, i.e., whether the human body can benefit from these two harvesters and compensate the cost of carrying the devices during power generation. Then, the $\mathrm{TCOH}$ can be used to select appropriate parameters to build the prototypes with the goal of maximum electrical power output and minimum metabolic consumption. In this part, we compare the net metabolic power and the $\mathrm{TCOH}$ of the two models under different spring stiffness $k_{2}$ and gear ratios $i_{g}$. In the slip model, the trend of metabolic power consumption for each 
gear ratio presented in this paper is similar to the energy cost of the suspension system, calculated by Ackerman [24]. The metabolic power consumption increases when $w_{f}$ is close to the resonant walking frequency and the increase is less significant for higher gear ratio because of higher damping force. Previous researchers [21,41] have proved that minimizing the suspension damping force is beneficial for reducing metabolic power. In this work, except for mechanical damping force, the electrical damping force is produced to generate electrical power, so a higher gear ratio also causes a less significant reduction in metabolic power. Also, since we take the mass of the framework and harvester into account, the total metabolic power consumption with electrical engagement is higher than that with a normal backpack (Figure 4a). In other words, the TCOH is positive (Figure 5a). The TCOH firstly decreases and then increases with increased stiffness, and the best TCOH for the slip system is at the stiffness of $2000 \mathrm{~N} / \mathrm{m}$. In the range of $2000 \mathrm{~N} / \mathrm{m}$ to $5000 \mathrm{~N} / \mathrm{m}$, even though the electrical power is increasing, the faster increasing metabolic power makes the overall $\mathrm{TCOH}$ still rise.
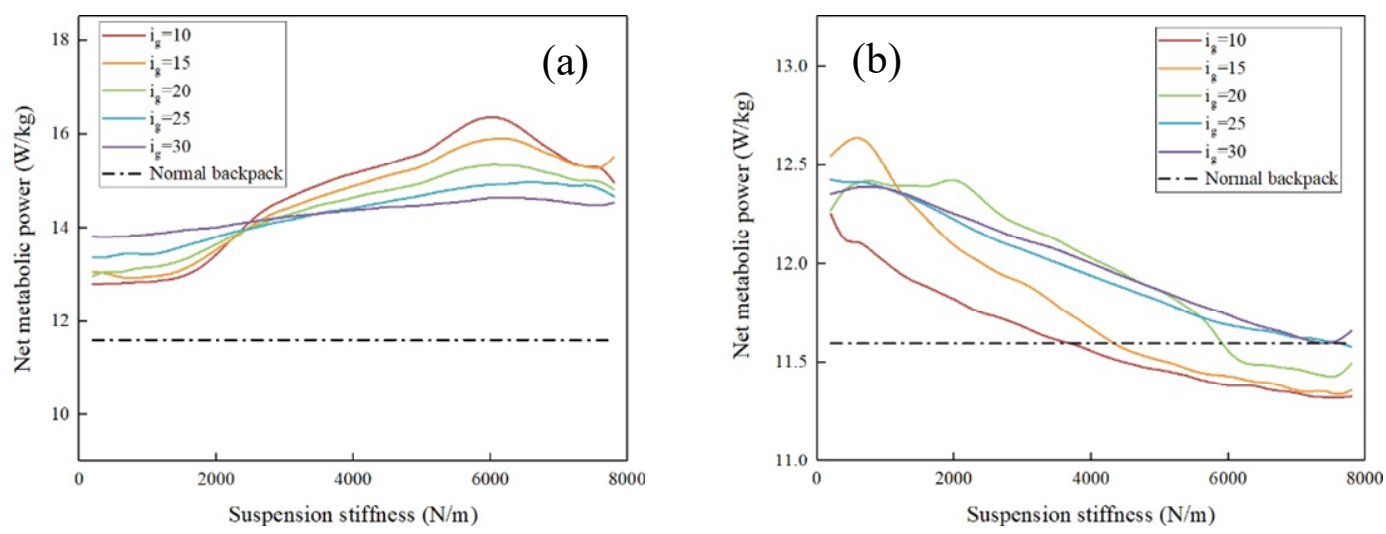

Figure 4. Net metabolic power versus spring stiffness under different gear ratios with walking velocity $v=5.5 \mathrm{~km} / \mathrm{h}$ and load mass $m_{l}=15 \mathrm{~kg}$ : (a) Slip model; (b) Swing model.
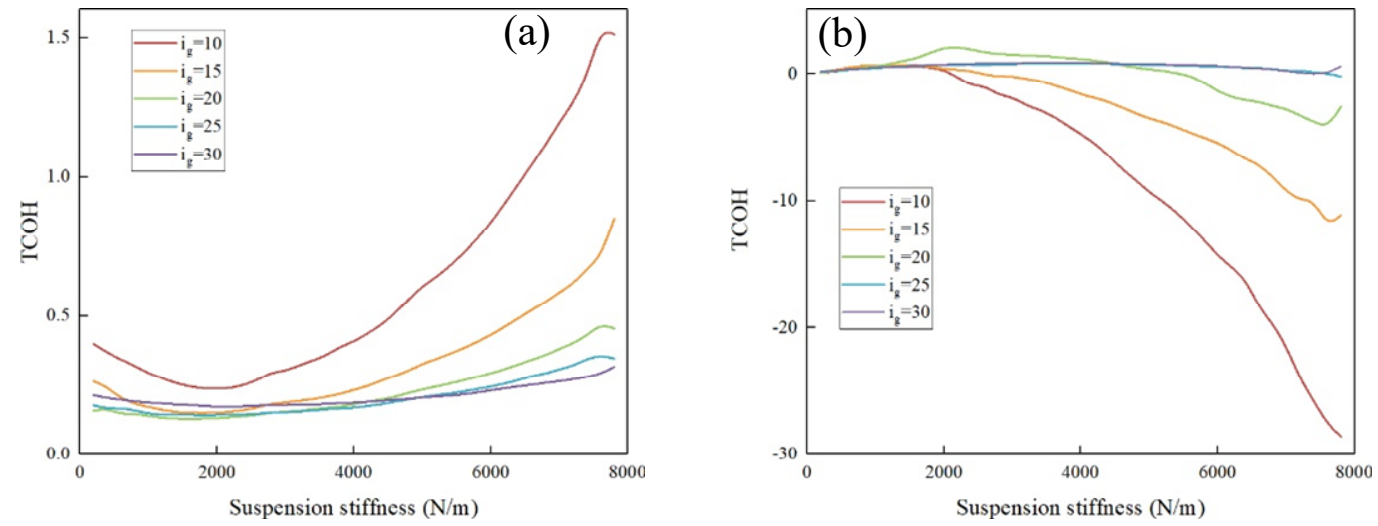

Figure 5. TCOH versus spring stiffness under different gear ratios with walking velocity $v=5.5 \mathrm{~km} / \mathrm{h}$ and load mass $m_{l}=15 \mathrm{~kg}$ : (a) Slip model; (b) Swing model.

In the swing model, due to the absence of a framework, the total metabolic power is slightly higher than that with a normal backpack, and a higher gear ratio leads to greater metabolic power. With the increase of the stiffness, the oscillating velocity decreases, and the metabolic power also decreases. In contrast to the slip model, the TCOH firstly increases and then decreases with increased stiffness, and higher stiffness even results in a faster reduction in metabolic cost than the output power, which causes the decrease of $\mathrm{TCOH}$. When the gear ratio was less than twenty, the $\mathrm{TCOH}$ can be negative in theory. It can be seen that the metabolic power and the TCOH in the swing model were lower than in the slip model. However, since one of the purposes of designing power generating 
backpacks was to produce electrical power for electric equipment, the relatively low output power limits the adjustment range of stiffness, which also indirectly restricts the maximum mass of the load.

\section{Experimental Validation}

\subsection{Human Walking Experimentation}

To evaluate our models, the FT harvester and the TL harvester were built based on the maximum average output power and the best $\mathrm{TCOH}$ of the simulation results, and experiments were performed. The key parameters of these two prototypes are listed in Table 2. Three different conditions were used in the experiments: (1) The normal backpack condition (NOB); (2) the FT harvester based backpack condition (FTB); and (3) the TL harvester based backpack condition (TLB). In each condition, three male participants ( $\mathrm{N}=3$, age: $24 \pm 3$ years, height $=170 \pm 4 \mathrm{~cm}$, weight $=60 \pm 5 \mathrm{~kg}$ ) walked on a treadmill at different velocities of $5,5.5$ and $6 \mathrm{~km} / \mathrm{h}$ with external loads of $15 \mathrm{~kg}$, respectively. The information of these three participants is listed in Table 3. All participants were right-foot dominant, did not have musculoskeletal injuries or diseases, and provided informed consent. The procedures were approved by the Guangzhou First People's Hospital Department of Ethics Committee. Each session was applied for ten minutes of walking, and then a 35-min break was given after each session and before the start of another session. The order of the conditions was randomized. The participants were allowed at least a 24-hour break between conditions to minimize the impact of fatigue on metabolic power measurement.

Table 2. Parameters of the prototypes.

\begin{tabular}{ccc}
\hline Parameter & FT Harvester & TL Harvester \\
\hline Generator & DCX26L, Maxon & DCX26L, Maxon \\
Gear ratio & 21 & 21 \\
External load resistance $(\Omega)$ & 2 & 2 \\
Stiffness $(\mathrm{N} / \mathrm{m})$ & 2800 & 1200 \\
Weight of the harvester $(\mathrm{kg})$ & 1.5 & 1.5 \\
Weight of the framework $(\mathrm{kg})$ & 5 & 0 \\
\hline
\end{tabular}

Table 3. Information of the participants.

\begin{tabular}{ccccc}
\hline Participant & Gender & Age (years) & Height (cm) & Weight (kg) \\
\hline 1 & Male & 27 & 173 & 62 \\
2 & Male & 21 & 166 & 55 \\
3 & Male & 22 & 174 & 65 \\
\hline
\end{tabular}

An Oscilloscope was used to record the voltage on the external load resistance $R_{o}$, and then the output electrical power could be calculated. A breath-by-breath portable gas analyzer (Cosmed ${ }^{\circledR} \mathrm{K} 5$, Rome, Italy) was used to measure human metabolic cost. We calculated the metabolic power based on oxygen and carbon dioxide data gathered from each condition using the Brockway equation [42]. Net metabolic power was obtained by subtracting the resting metabolic power obtained during a standing test before each condition from the metabolic power performed during the conditions. The net metabolic power was then normalized by the body mass of each participant.

Statistical analysis was conducted in SPSS (ver. 24, IBM Corp., Armonk, NY, USA). To compare the mean results of each participant under different conditions, we used paired $t$ tests for multiple comparisons to verify the effect of the devices on metabolic cost and TCOH. The significance level was set at $p<0.05$ for all analyses. 


\subsection{Results}

The net metabolic cost was the lowest during the NOB condition under each walking velocity (Figure 6). The net metabolic cost for the TLB condition was $9.13 \pm 6.44 \%$ and $11.9 \pm 4.19 \%$ lower than that of the FTB condition at the velocity of 5.5 , and $6 \mathrm{~km} / \mathrm{h}$, respectively. Therefore, there was a reduction of $50.81 \pm 33.78 \mathrm{~W}$ and $70.51 \pm 25.47 \mathrm{~W}$ with the TLB condition compared with the FTB condition, respectively. However, there was no statistically significant difference between conditions.

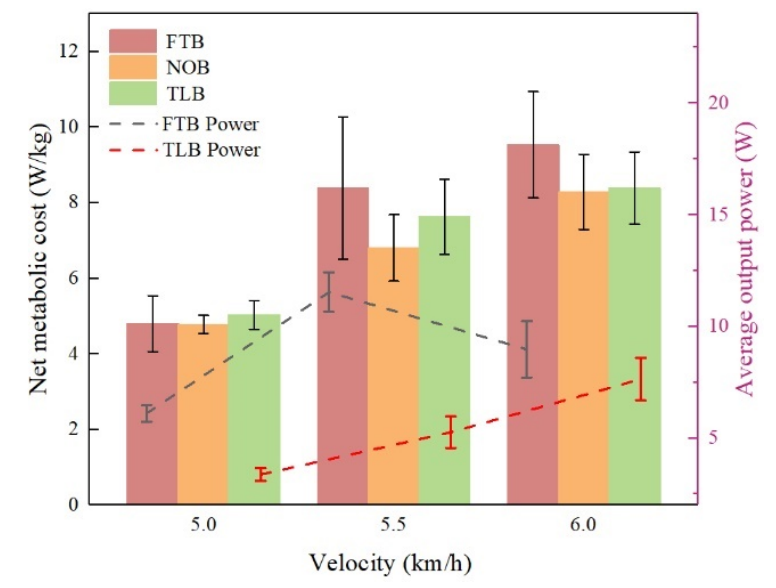

Figure 6. Net metabolic cost and average output power of walking for each condition. Data are means \pm SD.

For the FTB condition, the average output power was between $6.11 \mathrm{~W}$ and $11.53 \mathrm{~W}$, and the maximum output power occurred at the velocity of $5.5 \mathrm{~km} / \mathrm{h}$. For the TLB condition, the average output power was between $3.37 \mathrm{~W}$ and $7.64 \mathrm{~W}$. As the walking velocity increased, the output power also increased. When calculating the $\mathrm{TCOH}$, for the participant 1 , the $\mathrm{TCOH}$ was always positive, while for the participants 2 and 3, the best TCOH occurred at the velocity of $5 \mathrm{~km} / \mathrm{h}$, at which the TCOH of the participant 2 in the FTB and the TLB conditions was -0.15 , and -0.02 , respectively, and that of the participant 3 was -0.02 , and -0.05 , respectively (Figure 7). There was no significant difference between conditions.

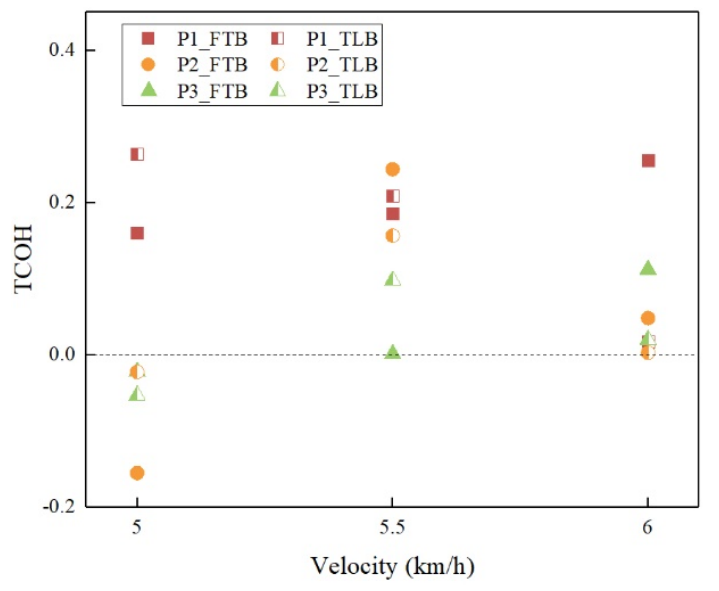

Figure 7. TCOH of three participants under three velocities. P1 represents the participant 1. FTB represents the FTB condition. TLB represents the TLB condition.

\section{Discussion}

This paper presented the power generation performance of the two types of energy harvesters, as well as the energy performance of human loaded walking while carrying energy harvesting 
backpacks. The trend of average output power was similar to that of simulation results. For all the participants under the FTB condition, the generated electrical power was the highest when the natural frequency of the load suspension was near the walking frequency, while under the TLB condition, the electrical power increased with the increase of velocity. It is worth noting that the average output power obtained in the experiment was lower than in the simulation. This is because the models only considered the movement of the human body at a fixed distance in the vertical direction. However, in the experiments, the hip displacement in the vertical direction, during walking, varies according to the height of the participant, and the upper limb would bend after backpacking, which could further reduce the relative distance and instantaneous speed between the energy harvester and the wearer. When the participants walked at $5.5 \mathrm{~km} / \mathrm{h}$ with a $15 \mathrm{~kg}$ load, the FT harvester and the TL harvester generated electrical power of $11.53 \mathrm{~W}$, and $5.26 \mathrm{~W}$, respectively. Rome's backpack harvester [16], when used with a $38 \mathrm{~kg}$ load, produced $7.4 \mathrm{~W}$ at a walking speed of $5.6 \mathrm{~km} / \mathrm{h}$. The Energy Harvesting Assault Pack (EHAP) [18] reported $1.5 \mathrm{~W}$ with a $15.9 \mathrm{~kg}$ load when walking at $4.83 \mathrm{~km} / \mathrm{h}$. Yuan's energy harvester [19] generated $3.29 \mathrm{~W}$ at a walking speed of $5.63 \mathrm{~km} / \mathrm{h}$ when used with a $13.6 \mathrm{~kg}$ load. When compared to others' work, the FT harvester generated higher electricity. Given that these two harvesters were built based on the simulation results, with a specific walking speed and load mass, the optimization of parameters can also help the harvesters perform better and generate more power, even though the energy harvesters keep having new designs.

The average metabolic cost was the lowest during the NOB condition, and this may due to the mass penalty and negative biomechanical effects of the harvesting system on the wearer, such as greater forward lean, which could cause increased shoulder pain [5,18]. Although there was no statistically significant difference, at the velocity of 5.5 and $6 \mathrm{~km} / \mathrm{h}$, all the participants consumed less metabolic energy in the NOB condition than in the other two conditions. This showed that the current energy harvesting backpacks could not reduce the human metabolic cost. Moreover, due to the weight of the framework, the average metabolic cost in the FTB condition was higher than in the TLB condition, but a statistically significant difference was also not found between the two conditions. For participant 2 , at the velocity of 5 and $5.5 \mathrm{~km} / \mathrm{h}$, the metabolic cost under the FTB condition was even lower than the TLB condition. Since the FT harvester was proved to relieve part of the accelerative load from the wearer, this may potentially help reduce the metabolic cost during loaded walking, as was observed by Rome et al. [20]. Compared with the simulation results, the net metabolic cost for all the participants was lower. This is because we used a higher weight of body load $(75 \mathrm{~kg})$ and calculated the mechanical work on the legs in the simulation, while in the experiments, the net metabolic power was obtained by subtracting the resting metabolic power. This eliminated the effect of loads on human metabolic consumption when standing.

During the experiments, the participants reported that it was harder for them to maintain body balance under the two harvesting conditions. This was in line with the findings of [43], which showed that the suspended load could affect the dynamic stability of human walking. When compared to normal backpack, the suspended-load backpacks were still limited to their additional mass and uncomfortable subjective feelings to the participants due to the relative motion of the human body, resulting in additional metabolic consumption. This awkward subject feeling could be improved by increasing the damping ratio of the load suspension to reduce oscillations and damp perturbations more quickly. However, it represented a design tradeoff because the generated electrical power and potential energetic benefits, which were offered by the suspension, would be compromised if the damping ratio was too high [43].

When comparing the TCOH between the two conditions, the TL harvester did not show an advantage at the velocity of 5 and $5.5 \mathrm{~km} / \mathrm{h}$ due to the low electrical power. At the velocity of $6 \mathrm{~km} / \mathrm{h}$, the electrical power generated by the TL harvester was slightly lower than the FT harvester, and the participants produced less additional metabolic energy, which resulted in lower TCOH values. With the increase of the velocity, the FT harvester may perform better on power generation and energy performance of human loaded walking. Moreover, for the participants 2 and 3, the TCOH was 
negative at the velocity of $5 \mathrm{~km} / \mathrm{h}$, which showed that although the average metabolic cost in the NOB condition was lower than in the other two conditions, the TCOH could help to express individual energy performance, and could be used in the individual optimization of the energy harvesters to improve user metabolic performance.

Although the two models were verified by experiments in this paper, some limitations should be noted. First, the models could only explain the energy performance when the CoM of the human body moves vertically in the sagittal plane, while the swing of the CoM in the horizontal plane was ignored. Therefore, a three-dimensional human walking model may help to better predict the electrical energy and human metabolic consumption. Additionally, in this experiment there were only three participants, thus more tests are needed to learn more about the interaction between the wearer and the harvester based backpack. Given that the participants performed differently with respect to the two energy harvesters at the same velocity, the stiffness and damping coefficients should be adjustable so that the device could be participant-specific for better performance.

\section{Conclusions}

In this study, we discussed the power generation performance of the two types of energy harvesters and the energy performance of human loaded walking, while carrying energy harvesting backpacks based on two different spring-mass-damper models. Experiments were performed to evaluate the performance of the two energy harvesting backpacks. It was found that the electrical power in the experiments showed similar trends to the simulation results, but the calculated electrical power and the net metabolic power were higher than that of the experiments. In addition, the results demonstrated that the TCOH could be negative, which indicated that there is a chance to generate electrical power of $6.11 \mathrm{~W}$ without increasing the metabolic cost while carrying energy harvesting backpacks. Also, the results suggest that a future design that conducts the optimization for individuals might be able to improve user metabolic performance.

Author Contributions: Conceptualization, L.H. and L.X.; methodology, L.H. and L.X.; software, R.W.; validation, L.H., R.W. and Z.Y.; formal analysis, L.H. and L.X.; investigation, R.W.; resources, L.H. and R.W.; data curation, L.H.; writing-original draft preparation, L.H.; writing—review and editing, L.H. and L.X.; visualization, L.H. and Z.Y.; supervision, L.X.; project administration, L.X.; funding acquisition, L.X. All authors have read and agreed to the published version of the manuscript.

Funding: This work was supported in part by the National Natural Science Foundation of China (Grant No. 51575188), Joint Fund of the Ministry of Education for Equipment pre-Research (6141A02033124), Research Foundation of Guangdong Province (Grant No. 2016A030313492 and 2019A050505001), and Guangzhou Research Foundation (Grant No. 201903010028).

Conflicts of Interest: The authors declare no conflict of interest.

\section{References}

1. Bastien, G.J.; Willems, P.A.; Schepens, B.; Heglund, N.C. Effect of load and speed on the energetic cost of human walking. Eur. J. Appl. Physiol. 2005, 94, 76-83. [CrossRef] [PubMed]

2. Holewijn, M. Physiological strain due to load carrying. Eur. J. Appl. Physiol. Occup. Physiol. 1990, 61, $237-245$. [CrossRef] [PubMed]

3. Birrell, S.A.; Hooper, R.H.; Haslam, R.A. The effect of military load carriage on ground reaction forces. Gait Posture 2007, 26, 611-614. [CrossRef] [PubMed]

4. Tilbury-Davis, D.C.; Hooper, R.H. The kinetic and kinematic effects of increasing load carriage upon the lower limb. Hum. Mov. Sci. 1999, 18, 693-700. [CrossRef]

5. Hadid, A.; Belzer, N.; Shabshin, N.; Zeilig, G.; Gefen, A.; Epstein, Y. The effect of mechanical strains in soft tissues of the shoulder during load carriage. J. Biomech. 2015, 48, 4160-4165. [CrossRef] [PubMed]

6. Hadid, A.; Katz, I.; Haker, T.; Zeilig, G.; Defrin, R.; Epstein, Y.; Gefen, A. Effect of Load Carriage on Upper Limb Performance. Med. Sci. Sports Exerc. 2017, 49, 1006-1014. [CrossRef]

7. Xie, L.; Du, R. Harvest human kinetic energy to power portable electronics. J. Mech. Sci. Technol. 2012, 26, 2005-2008. [CrossRef] 
8. Von Buren, T.; Mitcheson, P.D.; Green, T.C.; Yeatman, E.M.; Holmes, A.S.; Troster, G. Optimization of inertial micropower generators for human walking motion. IEEE Sens. J. 2006, 6, 28-38. [CrossRef]

9. Romero, E.; Warrington, R.O.; Neuman, M.R. Body motion for powering biomedical devices. In Proceedings of the 2009 Annual International Conference of the IEEE Engineering in Medicine and Biology Society, Minneapolis, MN, USA, 3-6 September 2009; pp. 2752-2755.

10. Paradiso, J.A.; Starner, T. Energy scavenging for mobile and wireless electronics. IEEE Pervasive Comput. 2005, 4, 18-27. [CrossRef]

11. Granstrom, J.; Feenstra, J.; Sodano, H.A.; Farinholt, K. Energy harvesting from a backpack instrumented with piezoelectric shoulder straps. Smart Mater. Struct. 2007, 16, 1810. [CrossRef]

12. Martin, J.-P.; Li, Q. Design, model, and performance evaluation of a biomechanical energy harvesting backpack. Mech. Syst. Signal Process. 2019, 134, 106318. [CrossRef]

13. Elvin, N.G.; Elvin, A.A. Vibrational energy harvesting from human gait. IEEE/ASME Trans. Mechatron. 2012, 18, 637-644. [CrossRef]

14. Kuang, Y.; Ruan, T.; Chew, Z.J.; Zhu, M. Energy harvesting during human walking to power a wireless sensor node. Sens. Actuators A Phys. 2017, 254, 69-77. [CrossRef]

15. Ando, B.; Baglio, S.; Marietta, V.; Pistorio, A.; Bulsara, A.R. Preliminary investigation of a mixed inductive-piezoelectric energy harvester from human walking. In Proceedings of the IEEE Sensors Applications Symposium, Glassboro, NJ, USA, 13-15 March 2017.

16. Rome, L.C.; Flynn, L.; Goldman1, E.M.; Yoo1, T.D. Generating Electricity While Walking with Loads. Science 2005, 309, 1725-1728. [CrossRef] [PubMed]

17. Xie, L.; Cai, M. Increased energy harvesting and reduced accelerative load for backpacks via frequency tuning. Mech. Syst. Signal Process. 2015, 58-59, 399-415. [CrossRef]

18. Talarico, M.K.; Haynes, C.A.; Douglas, J.S.; Collazo, J. Spatiotemporal and kinematic changes in gait while carrying an energy harvesting assault pack system. J. Biomech. 2018, 74, 143-149. [CrossRef] [PubMed]

19. Yue, Y.; Liu, M.; Tai, W.C.; Lei, Z. Design and Treadmill Test of a Broadband Energy Harvesting Backpack With a Mechanical Motion Rectifier. J. Mech. Des. 2018, 140, 085001. [CrossRef]

20. Rome, L.C.; Flynn, L.; Yoo, T.D. Rubber bands reduce the cost of carrying loads. Nature 2006, 444, $1023-1024$. [CrossRef]

21. Hoover, J.; Meguid, S. Performance assessment of the suspended-load backpack. Int. J. Mech. Mater. Des. 2011, 7, 111-121. [CrossRef]

22. Foissac, M.; Millet, G.Y.; Geyssant, A.; Freychat, P.; Belli, A. Characterization of the mechanical properties of backpacks and their influence on the energetics of walking. J. Biomech. 2009, 42, 125-130. [CrossRef]

23. Xu, X.; Hsiang, S.M.; Mirka, G.A. The effects of a suspended-load backpack on gait. Gait Posture 2009, 29, 151-153. [CrossRef] [PubMed]

24. Ackerman, J.; Seipel, J. A model of human walking energetics with an elastically-suspended load. J. Biomech. 2014, 47, 1922-1927. [CrossRef] [PubMed]

25. Li, D.; Li, T.; Li, Q.; Liu, T.; Yi, J. A simple model for predicting walking energetics with elastically-suspended backpack. J. Biomech. 2016, 49, 4150-4153. [CrossRef] [PubMed]

26. Rubinshtein, Z.E.; Peretz, M.M.; Riemer, R. Biomechanical energy harvesting system with optimal cost-of-harvesting tracking algorithm. In Proceedings of the 2014 IEEE Applied Power Electronics Conference and Exposition-APEC 2014, Fort Worth, TX, USA, 16-20 March 2014; pp. 3105-3109.

27. Chen, M.; Yang, Z.; Saad, W.; Yin, C.; Poor, H.V.; Cui, S. A joint learning and communications framework for federated learning over wireless networks. arXiv 2019, arXiv:1909.07972.

28. Yang, Z.; Xu, W.; Pan, Y.; Pan, C.; Chen, M. Energy efficient resource allocation in machine-to-machine communications with multiple access and energy harvesting for IoT. IEEE Internet Things J. 2017, 5, 229-245. [CrossRef]

29. Mi, J.; Xu, L.; Zhu, Z.; Liu, M.; Zuo, L. Design, modeling and testing of a one-way energy harvesting backpack. In Proceedings of the Active and Passive Smart Structures and Integrated Systems XII, Denver, CO, USA, 10 April 2018; p. 1059520.

30. Xie, L.; Li, X.; Cai, S.; Huang, L.; Li, J. Increased energy harvesting from backpack to serve as self-sustainable power source via a tube-like harvester. Mech. Syst. Signal Process. 2017, 96, 215-225. [CrossRef]

31. Khaligh, A.; Zeng, P.; Zheng, C. Kinetic energy harvesting using piezoelectric and electromagnetic technologies-State of the art. IEEE Trans. Ind. Electron. 2009, 57, 850-860. [CrossRef] 
32. Wei, C.; Jing, X. A comprehensive review on vibration energy harvesting: Modelling and realization. Renew. Sustain. Energy Rev. 2017, 74, 1-18. [CrossRef]

33. Shepertycky, M.; Li, Q. Generating Electricity during Walking with a Lower Limb-Driven Energy Harvester: Targeting a Minimum User Effort. PLoS ONE 2015, 10. [CrossRef]

34. Ackerman, J.; Seipel, J. Energy efficiency of legged robot locomotion with elastically suspended loads. IEEE Trans. Robot. 2013, 29, 321-330. [CrossRef]

35. Inman, V.T.; Eberhart, H.D. The major determinants in normal and pathological gait. JBJS 1953, 35, 543-558.

36. Grieve, D.; Gear, R.J. The relationships between length of stride, step frequency, time of swing and speed of walking for children and adults. Ergonomics 1966, 9, 379-399. [CrossRef] [PubMed]

37. $\mathrm{Xu}, \mathrm{X}$. An Investigation on the Interactivity between Suspended-Load Backpack and Human Gait. Ph.D. Thesis, North Carolina State University, Raleigh, NC, USA, 2008.

38. Zhang, L.; Xu, D.; Makhsous, M.; Lin, F. Stiffness and viscous damping of the human leg. In Proceedings of the 24th Annual Meeting of the American Society of Biomechanics, Chicago, IL, USA, 19-22 July 2000.

39. Tzu-wei, P.H.; Kuo, A.D. Mechanics and energetics of load carriage during human walking. J. Exp. Biol. 2014, 217, 605-613.

40. Margaria, R. Biomechanics and Energetics of Muscular Exercise; Oxford University Press: Oxford, MI, USA, 1976.

41. Keren, R.; Or, Y. Energy performance analysis of a backpack suspension system with a timed clutch for human load carriage. Mech. Mach. Theory 2018, 120, 250-264. [CrossRef]

42. Brockway, J.M. Derivation of formulae used to calculate energy expenditure in man. Hum. Nutr. Clin. Nutr. 1987, 41, 463-471. [PubMed]

43. Ackerman, J.; Potwar, K.; Seipel, J. Suspending loads decreases load stability but may slightly improve body stability. J. Biomech. 2017, 52, 38-47. [CrossRef] [PubMed]

(C) 2020 by the authors. Licensee MDPI, Basel, Switzerland. This article is an open access article distributed under the terms and conditions of the Creative Commons Attribution (CC BY) license (http://creativecommons.org/licenses/by/4.0/). 